Article

\title{
Increased Levels of Txa 2 Induced by Dengue Virus Infection in IgM Positive Individuals Is Related to the Mild Symptoms of Dengue
}

\author{
Eneida S. Oliveira ${ }^{1}$, Stella G. Colombarolli ${ }^{1}$, Camila S. Nascimento ${ }^{1}$, Izabella C. A. Batista ${ }^{1}$, \\ Jorge G. G. Ferreira ${ }^{1}$, Daniele L. R. Alvarenga ${ }^{1}$, Laís O. B. de Sousa ${ }^{2}$, Rafael R. Assis ${ }^{1}$, \\ Marcele N. Rocha ${ }^{3}$, Érica A. R. Alves ${ }^{1, *}$ and Carlos E. Calzavara-Silva ${ }^{1, *}$ \\ 1 Imunologia Celular e Molecular, Instituto René Rachou, Avenida Augusto de Lima, 1715, sala 406, \\ Belo Horizonte 30190-002, Brazil; eneida.oliveira@minas.fiocruz.br (E.S.O.); \\ stella.colombarolli@minas.fiocruz.br (S.G.C.); camila.nascimento@minas.fiocruz.br (C.S.N.); \\ izabellaandrade@minas.fiocruz.br (I.C.A.B.); jorge.ferreira@minas.fiocruz.br (J.G.G.F.); \\ daniele4.alvarenga@gmail.com (D.L.R.A.); rafael.assis@minas.fiocruz.br (R.R.A.) \\ 2 Santa Casa de Misericórdia de Santo Antônio do Monte, Santo Antônio do Monte 35560-000, Brazil; \\ lais.medicina2006@gmail.com \\ 3 Mosquitos Vetores: Endossimbiontes e Interação Patógeno-Vetor, Instituto René Rachou, \\ Belo Horizonte 30190-002, Brazil; marcele@minas.fiocruz.br \\ * Correspondence: erica.alves@minas.fiocruz.br (E.A.R.A.); calzavara@minas.fiocruz.br (C.E.C.-S.); \\ Tel.: +55-31-33497836 (É.A.R.A.); +55-31-33497711 (C.E.C.-S.)
}

Received: 2 February 2018; Accepted: 25 February 2018; Published: 28 February 2018

\begin{abstract}
The inflammatory process plays a major role in the prognosis of dengue. In this context, the eicosanoids may have considerable influence on the regulation of the Dengue virus-induced inflammatory process. To quantify the molecules involved in the cyclooxygenase and lipoxygenase pathways during Dengue virus infection, plasma levels of thromboxane A2, prostaglandin E2 and leukotriene B4; mRNA levels of thromboxane A2 synthase, prostaglandin E2 synthase, leukotriene A4 hydrolase, cyclooxygenase-2 and 5-lipoxygenase; and the levels of lipid bodies in peripheral blood leukocytes collected from IgM-positive and IgM-negative volunteers with mild dengue, and non-infected volunteers, were evaluated. Dengue virus infection increases the levels of thromboxane A2 in IgM-positive individuals as well as the amount of lipid bodies in monocytes in IgM-negative individuals. We suggest that increased levels of thromboxane A2 in IgM-positive individuals plays a protective role against the development of severe symptoms of dengue, such as vascular leakage.
\end{abstract}

Keywords: Dengue virus; eicosanoids; cyclooxygenase-2; 5-lipoxygenase; lipid bodies

\section{Introduction}

Dengue is an arthropod-borne viral disease caused by any of the four Dengue virus (DENV) serotypes (DENV-1 to -4). This virus belongs to the Flaviviridae family and is transmitted to humans through the bite of infected female mosquitoes of the genus Aedes. Dengue occurs in more than 128 countries in tropical and subtropical regions worldwide and is considered the most prevalent mosquito-borne viral disease affecting humans [1]. It is estimated that 3.9 billion people are at risk for DENV infection. In addition, an estimated 500,000 people with dengue require hospitalization each year, and approximately $2.5 \%$ of those affected will die [2].

In humans, after an incubation period of 4-8 days, DENV can induce a wide spectrum of illness, with most cases being asymptomatic or subclinical. Most patients recover after a self-limiting illness, while a small proportion of patients progresses to a severe disease state, which is primarily 
characterized by plasma leakage with or without bleeding [3]. The clinical course of dengue is influenced by multiple factors, such as DENV tropism and virulence, viral load, activation of the complement system, humoral and cellular immune response, as well as cytokines produced during DENV infection [4]. Furthermore, it is well known that the inflammatory process and the regulation thereof play major roles in the prognosis of dengue $[5,6]$. An exacerbated inflammatory response can trigger systemic tissue injury, leading to endothelial permeability, edema, inflammatory exudates and hematological abnormalities, such as leucopoenia and anemia [7]. In this context, eicosanoid molecules, which are bioactive signaling lipids, have considerable influence on the regulation of many inflammatory mechanisms involved in the pathogenesis of several diseases [8]. However, few studies have analyzed the role of eicosanoids during DENV infection [9-11].

In mammalian cells, eicosanoids can be synthesized within different cell compartments, including lipid bodies (LBs) [12]. These organelles are composed of a lipid core and a surface phospholipid monolayer. The core of the LB is composed of triglycerides, cholesterol esters and proteins, which are generally embedded in or adherent to the surface [13]. In the past, LBs were largely associated with lipid storage, but they are now recognized as dynamic and functionally active organelles involved in a variety of cellular functions, including lipid metabolism, cell signaling and inflammation [14]. LBs act as viral assembly platforms for several viruses, such as hepatitis $C$ viruses, rotavirus, orthoreoviruses and DENV, participating primarily in viral encapsidation $[15,16]$. These organelles have been reported as the content of cytoplasmic vacuoles in macrophages [17], which have been observed the presence of DENV, facilitating viral replication [18].

The biosynthesis of eicosanoids depends on the availability of free arachidonic acid (AA). When tissues are exposed to diverse physiological and pathological stimuli, AA is produced from membrane phospholipids by phospholipase $\mathrm{A}_{2}$ and can then be converted by different enzymatic pathways into eicosanoids. In the cyclooxygenase (COX) pathway, free AA is converted into prostaglandin $\mathrm{H}_{2}$ $\left(\mathrm{PGH}_{2}\right)$ by the action of the enzyme cyclooxygenase- 1 or cyclooxygenase-2 (COX-2). Then, $\mathrm{PGH}_{2}$ is subsequently converted by cell-specific synthases into biologically active products, including prostaglandins and thromboxanes. In the lipoxygenase (LOX) pathway, AA can be converted into leukotrienes by different enzymes, including the enzyme 5-lipoxygenase (5-LOX) [8].

The eicosanoids of the COX pathway regulate a wide spectrum of processes. They elicit the cardinal signs of inflammation [19] and can also modulate the functions of neutrophils, monocytes, dendritic and natural killer cells, and T and B lymphocytes. In addition, some eicosanoids of the COX pathway induce vasoconstriction, activation of endothelial cells, and the activation and aggregation of platelets. On the other hand, the eicosanoids of the LOX pathway promote the recruitment of leukocytes, such as neutrophils, eosinophils, monocytes/macrophages, mastocytes, dendritic cells and effector $\mathrm{T}$ cells to sites of tissue damage [20]. These eicosanoids also induce the synthesis of pro-inflammatory cytokines by monocytes, as well as cytotoxicity mediated by NK cells and the differentiation of B-lymphocytes into IgE-producing cells [21].

Few studies have shown that eicosanoid-forming enzymes and their products are affected by DENV infection. Preeyasombat et al. (1999) [9] reported that the levels of thromboxane $\mathrm{A}_{2}\left(\mathrm{TXA}_{2}\right)$, a product of the COX pathway, were lower in the plasma from patients with dengue shock syndrome [9]. In another study, Loke et al. [10] demonstrated that the levels of leukotriene $\mathrm{B}_{4}\left(\mathrm{LTB}_{4}\right)$, a product of LOX pathway, were higher in the plasma from patients during the febrile and defervescence stages of dengue. These authors also observed increased levels of $\mathrm{LTB}_{4}$ in the neutrophil culture supernatant, which they attributed to the increased expression of 5-LOX in these cells after in vitro DENV infection [10]. More recently, increased levels of prostaglandin $\mathrm{E}_{2}\left(\mathrm{PGE}_{2}\right)$, a product of the COX pathway, were detected in sera from patients during the febrile stage of dengue. Moreover, elevated COX-2 gene expression in blood cells from dengue patients has also been observed [11]. However, to date, there is no study simultaneously comparing the COX and LOX pathways and their products during the natural course of dengue. 
The aim of our study was to assess the plasma levels of $\mathrm{TXA}_{2}$ and $\mathrm{PGE}_{2}$ (products of the COX pathway) and $\mathrm{LTB}_{4}$ (product of the 5-LOX pathway). As LBs are organelles involved in the synthesis of eicosanoids, we also measured the level of eicosanoids in the peripheral blood leukocytes. In addition, we quantified the gene expression levels of $C O X-2$, thromboxane A2 synthase $\left(T X A_{2} S\right)$ and prostaglandin $\mathrm{E}_{2}$ synthase $\left(P G E_{2} S\right)$, which are involved in the production of $\mathrm{TXA}_{2}$ and $\mathrm{PGE}_{2}$, and the mRNA levels of 5-LOX and leukotriene A4 hydrolase $\left(L T A_{4} H\right)$, which are involved in the production of $\mathrm{LTB}_{4}$.

Here, we demonstrated that DENV infection may induce increased levels of $\mathrm{TXA}_{2}$ in IgM-positive dengue patients as well as an increased amount of LBs in the monocytes of IgM-negative dengue patients, suggesting that the balance of $\mathrm{TXA}_{2}$ and IgM levels plays a protective role against the development of severe symptoms of dengue, such as vascular leakage.

\section{Materials and Methods}

\subsection{Ethical Aspects}

This study was approved by the Ethics Committee from Instituto René Rachou/FIOCRUZ-MG (CAAE: 55135116.0.0000.5091, approved date: 18 August 2016). Participants involved in the study signed a written informed consent, and all analyzed data were anonymized.

\subsection{Study Population}

A cross-sectional study was conducted between March and May of 2017 in Santa Casa de Misericórdia de Santo Antônio do Monte, Santo Antônio do Monte city, Minas Gerais state, Brazil. Twenty-eight adult patients, above the age of 18 , with a clinically characterized non-severe form of dengue infection were enrolled in the study. DENV infection was confirmed in the volunteers when at least one of the following tests was positive: (a) Dengue Virus NS1 ELISA (Euroimmun, Luebeck, Germany); (b) Anti-Dengue Virus ELISA (IgM) (Euroimmun); and (c) TRIOPLEX Dengue/Zika/ChikV kit (Eco Diagnóstica, Minas Gerais, Brazil). All dengue diagnostic tests were performed according to the manufacturer's instructions. Dengue patients were subsequently divided into two study groups according to the absence or presence of anti-DENV IgM in their plasma. Twelve individuals (11 women and 1 men; median age $=33$ years, range $=18.0$ to 85.0) comprised the IgM-positive group. Sixteen individuals (12 women and 4 men; median age $=37.5$ years, range $=18.0$ to 61.0 ) comprised the IgM-negative group. The non-infected control group was composed of twelve individuals (6 women and 6 men; median age $=32.5$ years, range $=27.0$ to 56.0 ) with no signs or symptoms of dengue and with negative results in all dengue diagnostic tests.

\subsection{Eicosanoids Quantification}

Plasma obtained by the centrifugation of whole blood was stored at $-80^{\circ} \mathrm{C}$. All samples were thawed only once, and the levels of eicosanoids were analyzed. Levels of $\mathrm{TXA}_{2}$ and $\mathrm{PGE}_{2}$ were indirectly assessed using the Thromboxane $B_{2}$ ELISA Kit and Prostaglandin E Metabolite ELISA Kit, respectively. Levels of $\mathrm{LTB}_{4}$ were directly quantified using the Leukotriene $\mathrm{B}_{4}$ ELISA Kit. All reagents were purchased from Cayman Chemical (Ann Arbor, MI, USA), and all reactions were performed according to the manufacturer's instructions.

\subsection{Immunofluorescence Staining}

Blood was centrifuged at $350 \times \mathrm{g}$, for $10 \mathrm{~min}$ at $18{ }^{\circ} \mathrm{C}$. Pelleted blood cells were homogenized, and the number of leukocytes in each sample was counted in Turk's solution (1:20) using a Neubauer chamber. An aliquot containing $5 \times 10^{5}$ leukocytes was resuspended in $1 \%$ bovine serum albumin (Sigma-Aldrich, St. Louis, MO, USA) in 0.15 M PBS contained in 5-mL polypropylene round-bottom tubes (Becton Dickinson, Franklin Lakes, NJ, USA). Leukocytes were stained for $20 \mathrm{~min}$ at room temperature, protected from light, with anti-CD16 Alexafluor 700 (Clone 3G8), anti-CD56 PE-Cy5 
(Clone B159), anti-CD3 PE (Clone UCHT1), anti-CD19 APC (Clone HIB19), anti-CD14 PerCP (Clone M4P-9), anti-CD45 V450 (Clone HI30), anti-CD4 APC (Clone RPA-T4) and anti-CD8 PerCP (Clone SK1), all purchased from BD Bioscience (Franklin Lakes, NJ, USA). Then, the leukocytes were stained for $20 \mathrm{~min}$ at room temperature with $5 \mu \mathrm{M}$ Bodipy 493/503 (ThermoFisher Scientific, Waltham, MA, USA) in 0.15 M PBS. After staining, the erythrocytes were lysed, and leukocytes were washed. Cells were resuspended in 0.15 M PBS and stored in the refrigerator prior to acquisition on the flow cytometer within $24 \mathrm{~h}$. Compensation was done using an Anti-Mouse Ig,K/Negative Control (FBS) Compensation Particles Set (BD Bioscience). Compensation parameters were calculated using the BD FACSDIVA 6.2 software (BD Bioscience). Data were acquired using the cytometer LSR Fortessa (BD Bioscience), and at least 200.000 events were acquired per sample. Data were analyzed using the FlowJo 10.1 software (FlowJo, Franklin Lakes, NJ, USA).

\section{5. mRNA Quantification}

Total RNA was extracted from peripheral blood leukocytes collected from DENV-infected individuals and healthy volunteers, using the PureLink ${ }^{\mathrm{TM}}$ RNA Mini Kit (ThermoFisher Scientific) following the manufacturer's protocols. The purified RNA (50 ng) was reverse transcribed to cDNA using the GoScript Reserve Transcription System with random primers (Promega, Madison, WI, USA) according to the manufacturer's instructions. The target genes were amplified and detected using TaqMan ${ }^{\circledR}$ gene expression assays (ThermoFisher Scientific, cat. number 4,331,182-gene id: PTGS2-Hs00153133_m1, TBXAS1-Hs01022706_m1, PTGES2-Hs00228159_m1, ALOX5-Hs00167536_m1, LTA4H-Hs01075871 and ACTB-Hs_99999903_m1). Then, RNase H (2 U) (ThermoFisher Scientific) was added and the samples were incubated at $37^{\circ} \mathrm{C}$ for $20 \mathrm{~min}$. The RT-qPCR was performed using the StepOnePlus ${ }^{\mathrm{TM}}$ Real-Time PCR System (ThermoFisher Scientific). Reactions were performed in triplicate and included $5 \mu \mathrm{L}$ of cDNA, $6.25 \mu \mathrm{M}$ of each target TaqMan ${ }^{\circledR}$ assay or human $\beta$-actin TaqMan ${ }^{\circledR}$ assay used to normalize the gene expression data, $7.5 \mu \mathrm{L}$ of $\operatorname{TaqMan}^{\mathrm{TM}}$ Gene Expression Master Mix (ThermoFisher Scientific) and water added to a final volume of $15 \mu \mathrm{L}$. Duplicates of non-template controls were included in each RT-qPCR experiment. The thermocycling conditions were as follows: initial holding $\left(2 \mathrm{~min}\right.$ at $50^{\circ} \mathrm{C}$ and $10 \mathrm{~min}$ at $\left.95^{\circ} \mathrm{C}\right)$, followed by 40 cycles of $15 \mathrm{~s}$ at $95^{\circ} \mathrm{C}$ and $1 \mathrm{~min}$ at $60^{\circ} \mathrm{C}$. The baseline and threshold for the cycle threshold $(\mathrm{Ct})$ calculations were set automatically using the Sequence Detection Software, version 1.4 (Applied Biosystems, Waltham, MA, USA). The $2^{-\Delta \Delta C t}$ method was used to calculate the relative quantification [22,23], using the mean of all of the NI samples as the reference value.

\subsection{Dengue Virus Load Quantification}

Total nucleic acids were extracted from $240 \mu \mathrm{L}$ of plasma that was centrifuged at $20,000 \times g$ for $1.5 \mathrm{~h}$ at $4{ }^{\circ} \mathrm{C}$ to concentrate the viral particles. After centrifugation, the supernatant was discarded and $50 \mu \mathrm{L}$ of buffer containing Tris Base (Inlab, São Paulo, Brazil), EDTA (Synth, São Paulo, Brazil), $\mathrm{NaCl}$ (Synth) and proteinase K (Qiagen, Hilden, Germany) was added. All samples were subsequently processed in the Thermal Cycler Veriti (ThermoFisher Scientific), at $56^{\circ} \mathrm{C}$ for $5 \mathrm{~min}$ and $98^{\circ} \mathrm{C}$ for $15 \mathrm{~min}$. Then, the obtained nucleic acids were used to determine the DENV viral load (number of DENV RNA copies per $\mathrm{mL}$ of plasma), which was quantified using a LightCycler ${ }^{\circledR} 96$ (Roche, Mannheim, Germany) and the following primers and probe: DENV-F: 5'-AAG GAC TAG AGG TTA GAG GAG ACC C-3', DENV-R: 5'-CGT TCT GTG CCT GGA ATG ATG-3' and DENV-Probe: 5'-/TEX615/AAC AGC ATA TTG ACG CTG GGA GAG ACC AGA/3IAbRQSp/3' [24]. Reactions were performed in duplicate and included $2.5 \mu \mathrm{L}$ of nucleic acids, $0.25 \mu \mathrm{L}$ of each primer, $0.1 \mu \mathrm{L}$ of probe, $2.5 \mu \mathrm{L}$ of TaqMan Fast Virus 1-Step Master Mix (ThermoFisher Scientific) and water added to a final volume of $10 \mu \mathrm{L}$. Duplicates of non-template controls were included in the RT-qPCR assays. Thermocycling conditions were as follows: initial holding $\left(20 \mathrm{~s}\right.$ at $\left.95^{\circ} \mathrm{C}\right)$ followed by 40 cycles of $3 \mathrm{~s}$ at $95^{\circ} \mathrm{C}$ and $30 \mathrm{~s}$ at $60^{\circ} \mathrm{C}$. For quantification purposes, the sequences of the DENV amplicons ( $\left.3^{\prime} \mathrm{UTR}\right)$, were cloned 
(pGEMT-Easy plasmid, Promega), amplified and then serially diluted to generate a standard curve, as previously described by Richardson et al. (2006) [25].

\subsection{Analyses of Vacuolated Monocytes}

The morphology of the monocytes was analyzed using blood smears stained with a hematology staining kit (Instant-Prov, Newprov, Paraná, Brazil), according to the manufacturer's instructions. The percentage of vacuolated monocytes was determined by counting one hundred cells using light microscopy at $1000 \times$ magnification.

\subsection{Statistical Analysis}

The D'Agostino and Pearson omnibus test was used to evaluate the normality of data distribution. ANOVA, followed by the Student Newman-Keuls method, was used to compare multiple normal samples. The Kruskal-Wallis test, followed by the Dunn's method, was used to compare multiple non-normal samples. The unpaired nonparametric Mann-Whitney $t$-test was used to evaluate the data of viral load. The Prism $6^{\circledR}$ software package (GraphPad Software, San Diego, CA, USA) was used for statistical tests. Differences were considered significant when a $p$ value $\leq 0.05$ was obtained.

\section{Results}

\subsection{Dengue Diagnosis}

Out of 40 volunteers enrolled in this study, 12 healthy volunteers were considered non-infected by DENV, based upon negative results from RT-qPCR, ELISA NS1 and ELISA IgM tests. The 28 remaining volunteers presented dengue symptoms and were positive in at least one of the three tests used (17 were positive based upon RT-qPCR, 20 were positive based upon ELISA NS1 and 16 were positive based upon ELISA IgM). Thus, 28 volunteers were considered as DENV-infected subjects (Table 1). Due to the wide variation in days of symptoms reported by the volunteers (1-12 days of symptoms), the volunteers were divided into two groups according to the presence or absence of IgM.

Table 1. Profile of molecular and serological tests of volunteers.

\begin{tabular}{cccc}
\hline Volunteer & RT-qPCR & ELISA NS1 & ELISA IgM \\
\hline 1 & + & + & + \\
2 & + & - & - \\
3 & - & - & + \\
4 & + & + & + \\
5 & + & - & - \\
6 & - & - & + \\
7 & - & + & + \\
8 & + & + & - \\
9 & + & + & - \\
10 & - & + & - \\
11 & - & + & + \\
12 & + & + & - \\
13 & - & + & + \\
14 & - & + & - \\
15 & - & + & + \\
16 & + & + & + \\
17 & - & + & + \\
18 & + & + & + \\
19 & + & + & - \\
20 & + & - & - \\
21 & + & - & + \\
22 & - & + & - \\
23 & + & + & - \\
24 & + & & + \\
\hline
\end{tabular}


Table 1. Cont

\begin{tabular}{cccc}
\hline Volunteer & RT-qPCR & ELISA NS1 & ELISA IgM \\
\hline 25 & + & + & - \\
26 & - & - & + \\
27 & + & + & + \\
28 & + & - & + \\
29 & - & - & - \\
30 & - & - & - \\
31 & - & - & - \\
32 & - & - & - \\
33 & - & - & - \\
34 & - & - & - \\
35 & - & - & - \\
36 & - & - & - \\
37 & - & - & - \\
38 & - & - & - \\
39 & - & - & \\
40 & - &
\end{tabular}

\subsection{Plasma from IgM-Positive Individuals Has Increased Levels of $\mathrm{TX}_{2}$}

To evaluate the impact of DENV infection on the production of eicosanoids, we assessed the levels of TXA ${ }_{2}$ and $\mathrm{PGE}_{2}$, by measuring their stable metabolites, and LTB4 in the plasma from DENV-infected individuals. As shown in Figure 1, the IgM-positive group displayed higher plasma levels of TXA ${ }_{2}$ compared with the non-infected group $(555.9 \mathrm{pg} / \mathrm{mL}$ versus $155.3 \mathrm{pg} / \mathrm{mL} ; p<0.05)$ and the IgM-negative group $(555.9 \mathrm{pg} / \mathrm{mL}$ versus $141.3 \mathrm{pg} / \mathrm{mL} ; p<0.01)$. The plasma levels of PGE $_{2}$ and $\mathrm{LTB}_{4}$ were not significantly altered by the DENV infection.
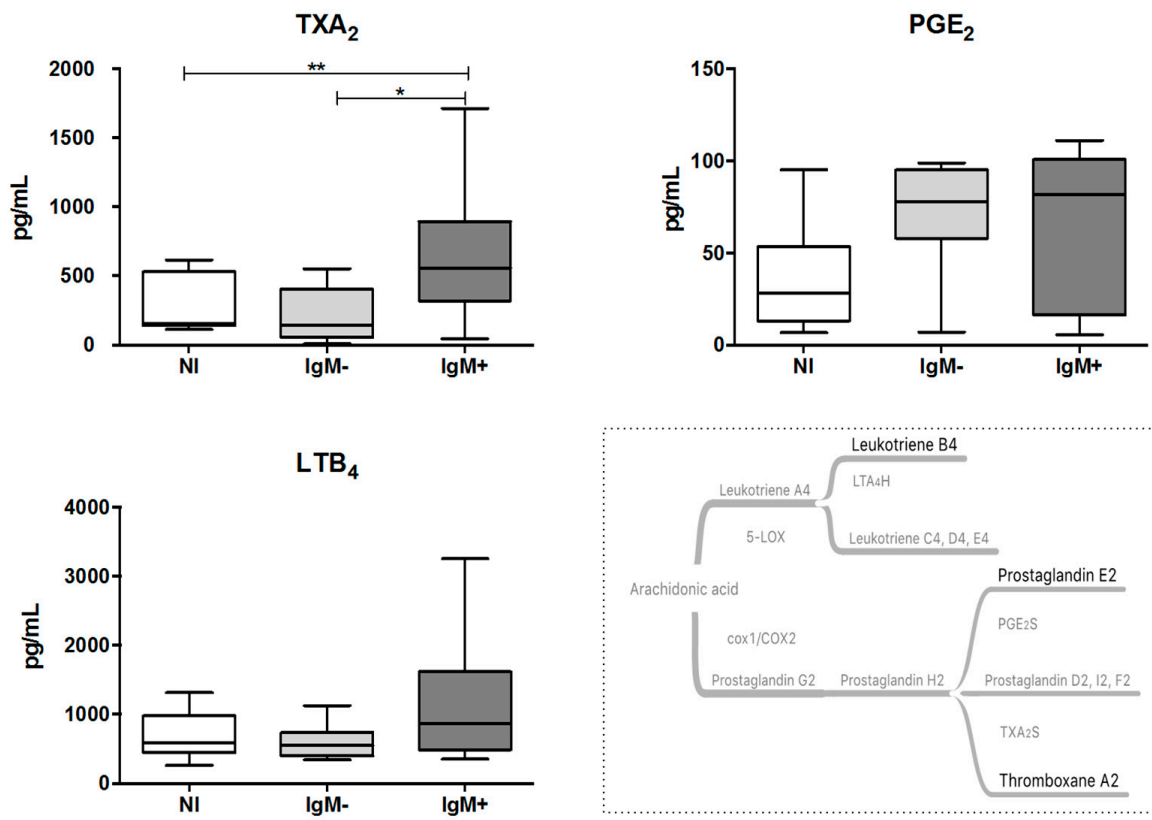

Figure 1. Quantification of eicosanoid $\mathrm{TXA}_{2}, \mathrm{PGE}_{2}$ and $\mathrm{LTB}_{4}$ in plasma from dengue-infected individuals. The eicosanoids were quantified in plasma samples using commercial ELISA kits. Data represent the median, quartiles and extreme values. $\mathrm{NI}=$ Non-infected individuals $(n=12)$. $\operatorname{IgM}^{-}=$DENV-infected individuals showing the absence of IgM in plasma $(n=12) . \operatorname{IgM}^{+}=\mathrm{DENV}-$ infected individuals showing the presence of $\operatorname{IgM}$ in plasma $(n=1) .\left(^{*}\right) p<0.05$ and $\left(^{* *}\right) p<0.01, \mathrm{TXA}_{2}$ and $\mathrm{LTB}_{4}$ were determined by ANOVA/Student Newman-Keuls test, and $\mathrm{PGE}_{2}$ was determined by the Kruskal-Wallis/Dunn's method. 


\subsection{Monocytes from IgM-Negative Individuals Displayed Increased Levels of LBS}

To investigate the effect of DENV infection on the levels of LBs in the peripheral blood leukocytes, we measured the median fluorescence intensity (MFI) of Bodipy 493/503, a green fluorescent dye that binds to the neutral lipids in LBs. Figure 2A shows that the MFI of Bodipy 493/503 in CD16 ${ }^{+}$ $(15,007$ versus 9238$)$ and $\mathrm{CD}^{-} 6^{-}(13,824$ versus 8806$)$ monocytes from the IgM-negative group was higher compared with the non-infected group $(p<0.05)$. In contrast, there was no difference in the MFI of Bodipy 493/503 when comparing subpopulations of monocytes from the non-infected and IgM-negative groups. The gating strategy used to analyze the monocytes is demonstrated in Figure $2 \mathrm{~B}$. DENV infection did not alter the MFI of Bodipy 493/503 in neutrophils, eosinophils, lymphocytes, NK and NK T cells [26].

A

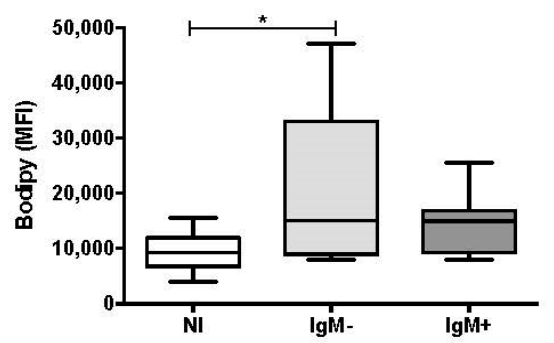

CD16-

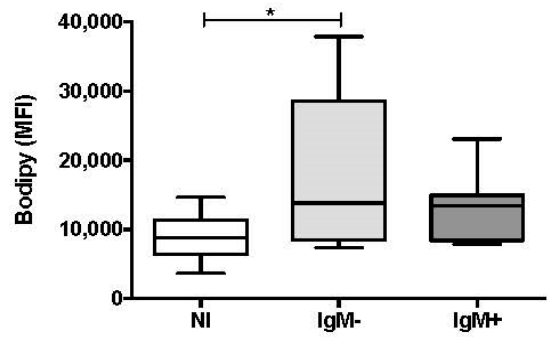

B
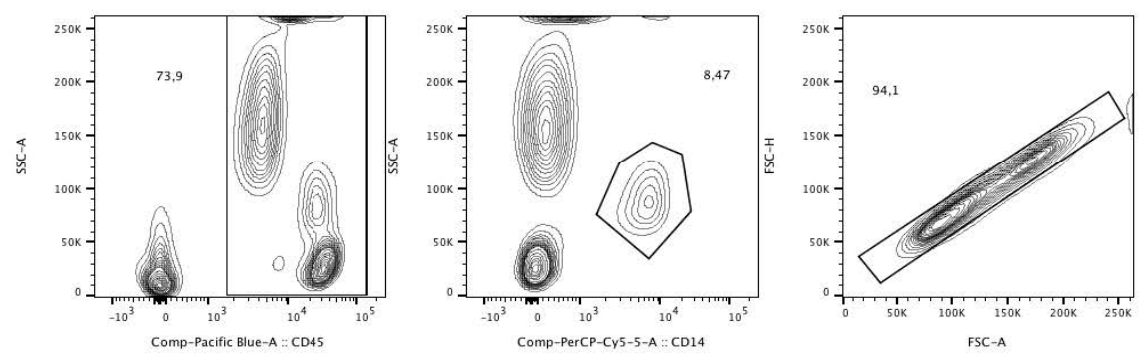
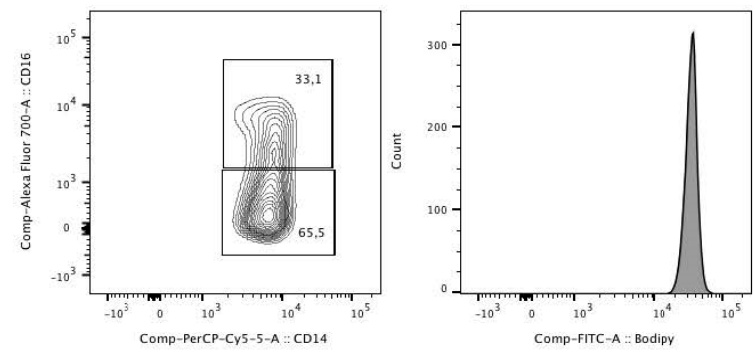

Figure 2. Lipid bodies in subpopulations of monocytes of dengue patients. (A) Effect of DENV infection on the median fluorescence intensities (MFI) of Bodipy 493/503 in CD16 $6^{+}$and CD16 ${ }^{-}$ monocytes, analyzed by flow cytometry. The antibodies used were anti-CD16 Alexafluor 700 (Clone 3G8), anti-CD14 PerCP (Clone M4P-9), and anti-CD45 V450 (Clone HI30). Data represent the median, quartiles and extreme values. NI, Non-infected individuals $(n=8)$; $\operatorname{IgM}^{-}$, DENV-infected individuals showing the absence of IgM in plasma $(n=10)$. IgM ${ }^{+}$, DENV-infected individuals showing the presence of IgM in plasma $(n=10) .\left(^{*}\right) p<0.05$. LB in both subpopulations of monocytes was determined by ANOVA/Student Newman-Keuls test; (B) gating strategy used in the flow cytometry analysis of LBs in subpopulations of monocytes from a dengue patient. Leukocytes were gated on a SSC-A versus CD45 plot. Monocytes were then further gated on a SSC-A versus CD14 plot. Next, single cells were gated on a FSC-H versus FSC-A plot. After that, $\mathrm{CD} 16^{+}$and $\mathrm{CD} 16^{-}$monocytes were gated on a CD14 versus $\mathrm{CD} 16$ plot. Histograms were used to obtain the median fluorescence intensity (MFI) of Bodipy $493 / 503$. 


\subsection{Expression Levels of COX-2 and $\mathrm{TX}_{2} S$ Genes Were Lower in Leukocytes from IgM-Positive Individuals}

The effect of DENV infection on the mRNA levels of genes coding for eicosanoid-forming enzymes, such as COX-2,TX $A_{2} S$ and $P G E_{2} S$ (COX pathway), and 5-LOX and $L T A_{4} H$ (5-LOX pathway), in peripheral blood leukocytes collected from DENV-infected individuals was assessed by qRT-PCR. We observed that the IgM-positive group presented lower levels of mRNA coding for the COX-2 gene $(0.22$ versus $0.58 ; p<0.05)$ and the $T X A_{2} S$ gene $(0.33$ versus $0.56 ; p<0.05)$ when compared to the non-infected group. The gene expression levels of $P G E_{2} S, 5-L O X$ and $L T A_{4} H$ were not altered by the DENV infection (Figure 3).
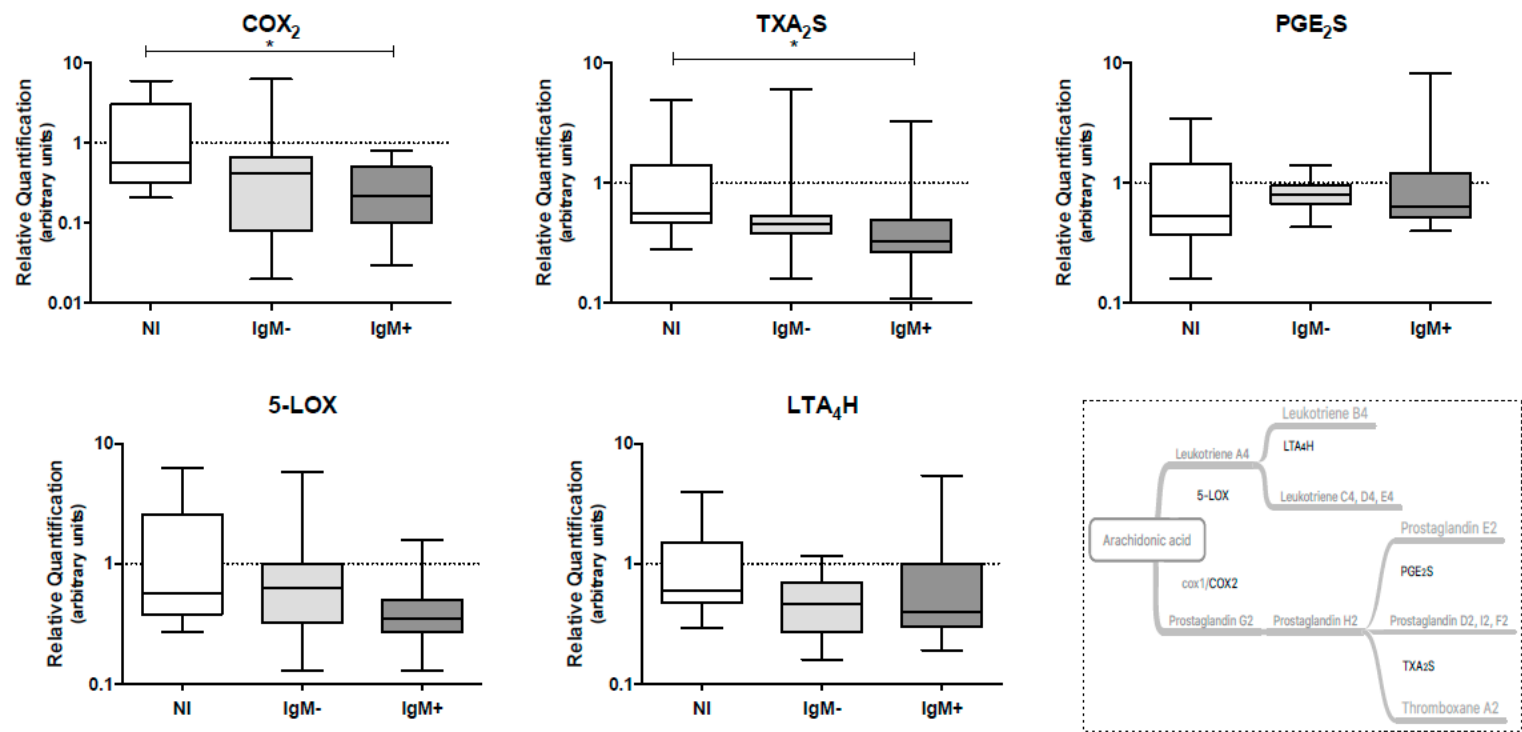

Figure 3. Quantification of mRNA levels coding for the eicosanoid-forming enzymes $\mathrm{COX}_{2}, \mathrm{TXA}_{2} \mathrm{~S}$, $\mathrm{PGE}_{2} \mathrm{~S}, 5-\mathrm{LOX}$ and $\mathrm{LTA}_{4} \mathrm{H}$ in peripheral blood leukocytes from dengue patients. The quantification of eicosanoid-forming enzymes was performed by RT-qPCR, using TaqMan ${ }^{\circledR}$ gene expression assays and human $\beta$-actin TaqMan ${ }^{\circledR}$ assay used to normalize the gene expression. Data represent the median, quartiles and extreme values. NI, Non-infected individuals $(n=12) ; \operatorname{IgM}^{-}$, DENV-infected individuals showing the absence of $\operatorname{IgM}$ in plasma $(n=12) ; \operatorname{IgM}^{+}, \mathrm{DENV}$-infected individuals showing the presence of $\operatorname{IgM}$ in plasma $\left.(n=15) .{ }^{*}\right) p<0.05$. All analyses were determined by the Kruskal-Wallis/Dunn's method.

\subsection{The Dengue Virus Load Was Higher in Plasma from IgM-Negative Patients}

To determine the viral load in the plasma of each dengue patient, we performed qRT-PCR. As shown in Figure 4A, an increase in the number of viral copies was observed in the IgM-negative group compared with the IgM-positive group $(13,335$ copies $/ \mathrm{mL}$ versus 0.0 copies $/ \mathrm{mL} ; p<0.001)$.

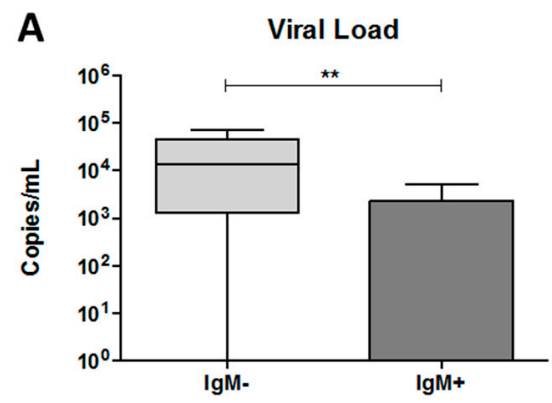

Figure 4. Cont. 

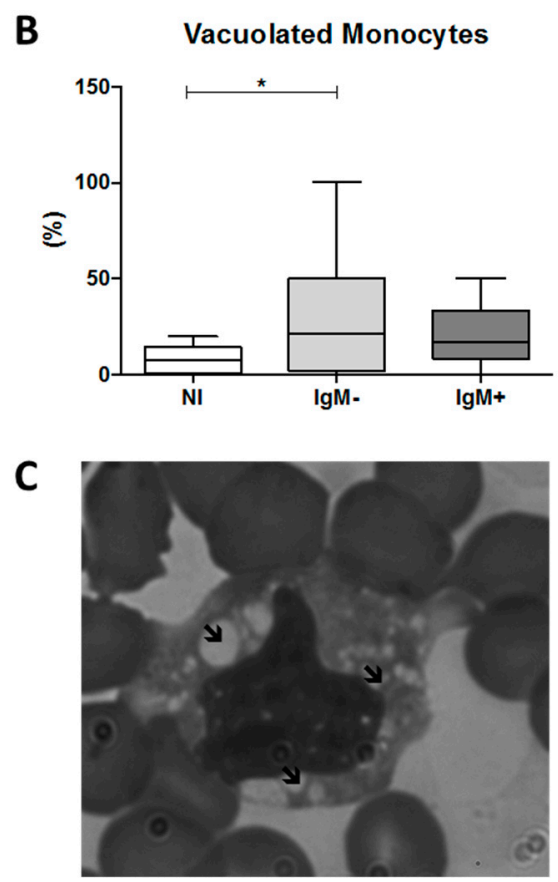

Figure 4. Quantification of DENV viral load and percentage of vacuolated monocytes in the blood collected from dengue patients. Data represent the median, quartiles and extreme values. (A) The quantification of viral load was performed by RT-qPCR. DENV RNA copies per mL of plasma. $\operatorname{IgM}^{-}$, DENV-infected individuals showing the absence of IgM in plasma $(n=12) ; \operatorname{IgM}^{+}$, DENV-infected individuals showing the presence of $\operatorname{IgM}$ in plasma $(n=16)$. The analysis was determined by the Mann-Whitney $t$-test; (B) percentage of vacuolated monocytes was determined using blood smears. NI $(n=12), \operatorname{IgM}^{-}(n=12), \operatorname{IgM}^{+}(n=11) .\left(^{*}\right) p<0.05$ and $\left(^{* *}\right) p<0.01$. The analysis was determined by ANOVA/Student Newman-Keuls test; (C) representative image of a vacuolated monocyte in the blood from a dengue patient, $1000 \times$ magnification. $\boldsymbol{K}=$ indicate the vacuoles.

\subsection{An Increased Percentage of Vacuolated Monocytes Was Observed in IgM-Negative Individuals}

To investigate whether DENV induces cytoplasmic vacuolization in monocytes, we assessed the percentage of vacuolated monocytes in blood smears from dengue patients. We observed that the IgM-negative group presented a percentage of vacuolated monocytes significantly higher than that of the non-infected group ( $21.6 \%$ versus $7.2 \% ; p<0.05$, Figure $4 \mathrm{~B})$. An example of a vacuolated monocyte in the blood from a DENV-infected individual is presented in Figure 4C.

\section{Discussion}

In this work, we aimed to evaluate whether DENV infection affects the synthesis of eicosanoids mediated by the COX and 5-LOX enzymes. Thus, the levels of TXA, $\mathrm{PGE}_{2}$ and $\mathrm{LTB}_{4}$, as well as the levels of mRNA coding for the TXA 2 S, PGE $E_{2} S$ and $L T A_{4} H, C O X-2$ and 5-LOX genes were assessed in blood collected from 28 DENV-infected individuals with mild symptoms and from non-infected volunteers. Based on the chronology of the humoral response to dengue [1,27], the infected individuals were subdivided into the IgM-negative group and IgM-positive group, representing the early and late stages of the acute phase of dengue, respectively.

Our data revealed increased levels of TXA 2 in IgM-positive dengue patients. Indeed, TXA 2 is one of the most potent eicosanoids involved in vasoconstriction and platelet aggregation [28]. Therefore, the increased levels of TXA 2 , associated with unaltered levels of the vasodilators $\mathrm{PGE}_{2}$ and $\mathrm{LTB}_{4}$, may have contributed to the absence of severe symptoms of dengue, such as vascular extravasation, in the individuals involved in our study. In fact, it has been suggested that TXA $\mathrm{A}_{2}$ may play a protective role in dengue, since decreased levels of TXA $\mathrm{T}_{2}$ in the blood of patients with dengue 
have been associated with the development of hypovolemic shock signals [9]. Moreover, $\mathrm{PGE}_{2}$ seems to play a deleterious role in dengue prognosis, since increased plasma levels of $\mathrm{PGE}_{2}$ were observed in a group of 11 individuals with dengue who developed vascular extravasation, as reported by Lin et al. (2017) [11].

$\mathrm{PGE}_{2}$ and $\mathrm{TXA}_{2}$ are synthesized from AA metabolism by the action of two cyclooxygenase isoforms, known as cyclooxygenase-1 (with constitutive expression) and COX-2 (inducible), to generate $\mathrm{PGH}_{2}$. Then, $\mathrm{PGH}_{2}$ can be converted by the enzymes $\mathrm{PGE}_{2} \mathrm{~S}$ or $\mathrm{TXA}_{2} \mathrm{~S}$ into $\mathrm{PGE}_{2}$ and $\mathrm{TXA}_{2}$, respectively. TXA 2 has a short half-life and is quickly converted to the stable but physiologically inactive metabolite thromboxane $\mathrm{B}_{2}$ [20]. The production of $\mathrm{LTB}_{4}$ begins when $\mathrm{AA}$ is metabolized by 5-LOX to form an unstable epoxy intermediate, which undergoes hydrolysis to generate leukotriene $A_{4}$. Then, leukotriene $A_{4}$ is converted to $\mathrm{LTB}_{4}$ by the action of the enzyme LTA 4 H [29]. TXA [30], $\mathrm{PGE}_{2}$, [31] and $\mathrm{LTB}_{4}[32]$ can be produced by various cells, including leukocytes. Therefore, to verify whether leukocytes were involved with the increased levels of $\mathrm{TX}_{2}$ observed after DENV infection and IgM production, we first quantified the LBs in the main peripheral blood leukocyte populations, since these organelles are the main sites of intracellular eicosanoid production [14].

We observed that the subpopulations of $\mathrm{CD} 16^{-}$and $\mathrm{CD}_{16}{ }^{+}$monocytes of the IgM-negative group displayed higher levels of LBs compared with the non-infected group, whereas the other leucocytes presented levels of LBs similar to those of the uninfected group, independent of presence or absence of IgM [26]. In fact, Samsa et al. (2009) [33] observed that BHK cells presented an increased number of LBs after in vitro infection by DENV-2. The authors postulated that the LBs sequester DENV capsid proteins and participate in the encapsidation of the DENV genome [33]. In addition, Carvalho et al., (2012) [16] confirmed the interaction between viral capsid protein and the protein perilipin 3 (TIP47) from LBs [16]. Moreover, Assunção-Miranda et al. (2010) [34] demonstrated that the peripheral blood leukocytes from dengue patients displayed increased amounts of LBs. However, in their study, the specific population of leukocytes that showed the increase of these organelles was not discriminated [34]. Our study, therefore, is the first to identify monocytes as the leukocytes that display altered levels of LBs in patients infected by DENV.

Thus, in this study, we suggest that the increase of the LB levels observed in monocytes of the IgM-negative group, despite not being associated with alterations in the plasma levels of eicosanoids or the mRNA levels of genes involved in eicosanoid-forming enzymes in leukocytes, is due to DENV infection and replication, since this increase was observed in the subpopulations of both positive and negative CD16 monocytes, both of which are permissive cells to viral infection and replication [35]. Our hypothesis is supported by the fact that the IgM-negative dengue patients also presented high DENV loads in the bloodstream. Moreover, the IgM-negative group presented a higher percentage of vacuolated monocytes in their blood, compared with the IgM-positive group. Corroborating our results, Mosquera et al. (2005) [18] also observed high vacuolization in human monocytes after in vitro infection with DENV-2 [18].

Because gene expression levels of $C O X-2$ and $T X A_{2} S$, which are involved in $\mathrm{TXA}_{2}$ production, were lower in the IgM-positive group, we hypothesize that other sources of TXA $\mathrm{A}_{2}$, such as platelets and/or vascular endothelial cells, both of which are activated after DENV infection [36,37], may have contributed to the elevated TXA 2 plasma levels of the IgM-positive group. In fact, platelets are the major source of $\mathrm{TXA}_{2}$ in vivo [30], and it has been observed that endothelial cells are also able to synthesize TXA 2 [38]. In this context, a recent study conducted by Lin et al. (2017) [11] reported an increase in COX-2 mRNA levels in whole blood of dengue patients who developed severe illness, whereas the patients involved in our study presented only mild symptoms of dengue [11]. Red blood cells and platelets may also express COX-2 [39,40], which may have contributed to the increased levels of COX-2 mRNA observed by the authors. Moreover, an in vitro study conducted by Loke et al. [10] in 2013 showed an increase in 5-LOX expression in neutrophils stimulated by DENV-2, which was followed by $\mathrm{LTB}_{4}$ production [10]. This contrasting result can be explained by the short time of exposure $(7 \mathrm{~h})$ and high viral load used in their study, which does not reflect the natural infection 
and, consequently, the progression of the disease or the immune response. Our work is the first that describes, ex vivo, the influence of DENV infection on the levels of $T X A_{2} S, P G E_{2} S$ and $L T A_{4} H$ mRNA.

Here, we propose a model for the role of LB and TXA 2 in dengue prognosis, as presented in Figure 5. During the time course of DENV infection, the virus triggers morphological and functional changes in monocytes, increasing the amount of LBs and vacuoles therein, which may be optimal sites of viral replication. Further, a high viral load and an unbalanced immune response could lead to the onset of dengue symptoms, including vascular damage with plasma leakage and bleeding. However, after seroconversion, characterized by the production of IgM, a high amount of TXA is produced, putatively by platelets and/or endothelial cells, which induces vasoconstriction and platelet aggregation, thereby preventing the intense vascular leakage and bleeding observed in severe dengue cases.

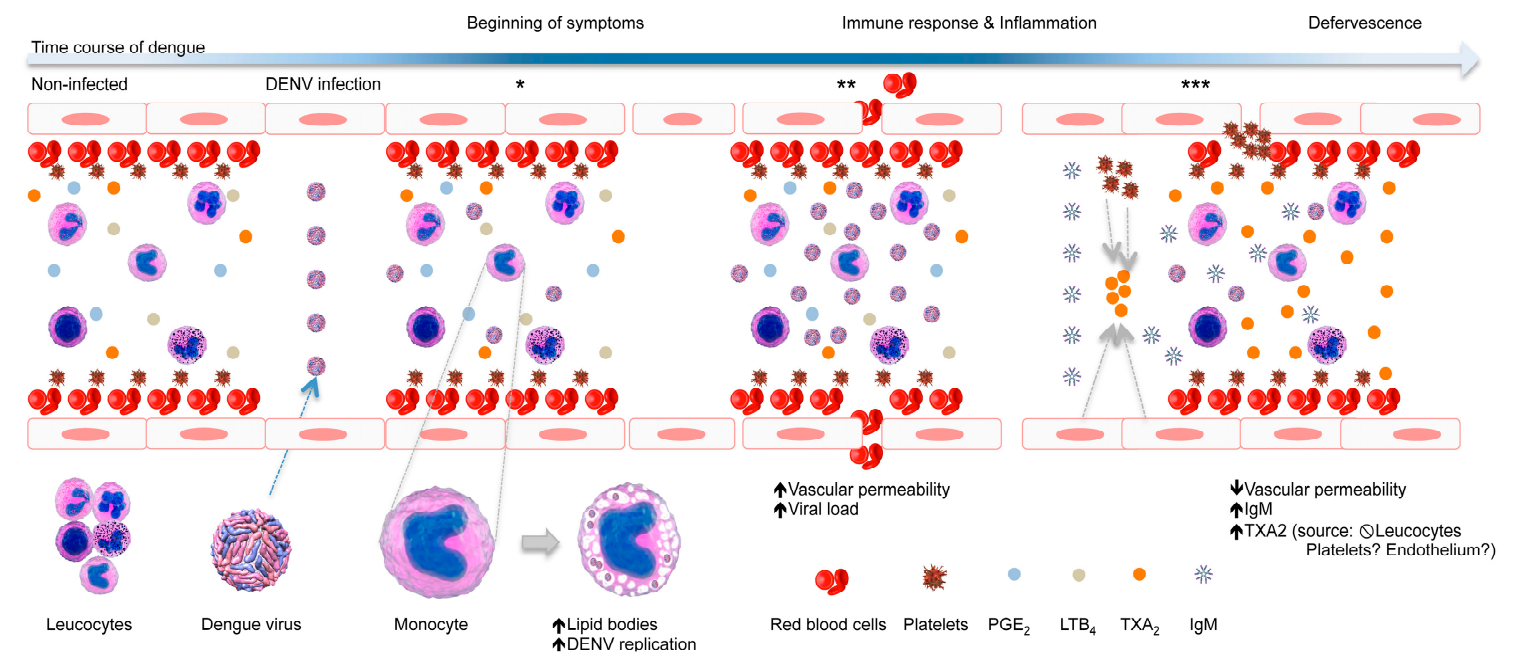

Figure 5. Schematic model of the role of LB and TXA $A_{2}$ in dengue prognosis. During the time course of DENV infection, the virus triggers morphological and functional changes in monocytes, increasing the amount of LBs and vacuoles, which may be optimal sites of viral replication $\left(^{*}\right)$. Further, a high viral load and an unbalanced immune response could lead to the onset of dengue symptoms, including vascular damage with plasma leakage and bleeding $\left.{ }^{* *}\right)$. However, after seroconversion, characterized by the production of IgM, high levels of $\mathrm{TXA}_{2}$ are produced, putatively by platelets and/or endothelial cells, which may trigger vasoconstriction and platelet aggregation, preventing the intense vascular leakage and bleeding observed in severe dengue cases $\left({ }^{* *}\right)$.

Taken together, our data led us to infer that during the early stages of the acute phase of dengue, when any or low levels of IgM can be detected, there is an increase in the levels of LBs in monocytes. Given that these cells are susceptible to DENV infection and the time course of infection coincides with the highest viral load but no concomitant changes were observed in the levels of mRNA coding for the enzymes involved in eicosanoids synthesis, we hypothesized that in the early stage of the disease, LBs are related to the replication of DENV in monocytes. We also concluded that the activation of the eicosanoid synthesis pathways occurs exclusively at the beginning of the defervescence of the disease, characterized by the production of TXA 2 . Since the individuals analyzed in our study did not develop severe dengue and $\mathrm{TXA}_{2}$ is a potent vasoconstrictor and platelet activator, we believe that this lipid mediator may play an important role in limiting the development of vascular leakage during DENV infection. More studies are warranted to investigate the role of LBs as well as the COX- and 5-LOX-mediated eicosanoid synthesis pathways during DENV infection. Finally, our data indicate that LBs could be interesting therapeutic targets to control viral replication during DENV infection and that eicosanoids may serve as important biomarkers of dengue prognosis. 
Acknowledgments: The authors thank Santa Casa de Misericórdia de Santo Antônio do Monte for the collaboration in the selection of volunteers, the Flow Cytometry Facility from Instituto René Rachou (Fiocruz-Minas) and the financial support from CNPq (439979/2016-1), CAPES (88887.116622/2016-01), Fiocruz/PAPES (401779/2015-7), CAPES and Programa de Pós-Graduação em Ciências da Saúde. We also thank Jaquelline G. Oliveira for her critical reading of this manuscript.

Author Contributions: Conception, design and supervision: Carlos E. Calzavara-Silva and Érica A. R. Alves. Methodological development: Eneida S. Oliveira, Stella G. Colombarolli, Camila S. Nascimento, and Izabella C. A. Batista. Data treatment and interpretation and statistical analysis: Carlos E. Calzavara-Silva, Érica A. R. Alves, Eneida S. Oliveira, and Rafael R. Assis. Recruitment and selection of volunteers: Eneida S. Oliveira and Laís O. B. de Sousa. Writing of the manuscript: Carlos E. Calzavara-Silva, Érica A. R. Alves, and Eneida S. Oliveira. Microscopy expertise: Érica A. R. Alves and Daniele L. R. Alvarenga. RT-qPCR expertise: Carlos E. Calzavara-Silva, Eneida S. Oliveira, Marcele N. Rocha, and Jorge G. G. Ferreira.

Conflicts of Interest: The authors declare no conflict of interest.

\section{Abbreviations}

$\begin{array}{ll}\text { COX } & \text { Cyclooxygenase } \\ \text { LOX } & \text { Lipoxygenase } \\ \mathrm{TXA}_{2} & \text { thromboxane A2 } \\ \mathrm{PGE}_{2} & \text { prostaglandin E2 } \\ \mathrm{LTB}_{4} & \text { leukotriene B4 } \\ \mathrm{TXA}_{2} \mathrm{~S} & \text { thromboxane A2 synthase } \\ \mathrm{PGE}_{2} \mathrm{~S} & \text { prostaglandin E2 synthase } \\ \mathrm{LTA}_{4} \mathrm{H} & \text { leukotriene A4 hydrolase } \\ \mathrm{COX}-2 & \text { cyclooxygenase-2 } \\ 5-L O X & \text { 5-lipoxygenase } \\ \mathrm{DENV} & \text { Dengue virus } \\ \mathrm{LB} & \text { lipid bodies } \\ \mathrm{AA} & \text { arachidonic acid } \\ \mathrm{PGH} & \text { prostaglandin } \mathrm{H} 2 \\ \mathrm{MFI} & \text { median fluorescence intensity } \\ \mathrm{N} & \text { Non-infected }\end{array}$

\section{References}

1. Guzman, M.G.; Gubler, D.J.; Izquierdo, A.; Martinez, E.; Halstead, S.B. Dengue infection. Nat. Rev. Dis. Prim. 2016, 2, 1-26. [CrossRef] [PubMed]

2. Bhatt, S.; Gething, P.W.; Brady, O.J.; Messina, J.P.; Farlow, A.W.; Moyes, C.L.; Drake, J.M.; Brownstein, J.S.; Hoen, A.G.; Sankoh, O.; et al. The global distribution and burden of dengue. Nature 2013, 496, 504-507. [CrossRef] [PubMed]

3. Lee, T.H.; Lee, L.K.; Lye, D.C.; Leo, Y.S. Current management of severe dengue infection. Expert Rev. Anti-Infect. Ther. 2017, 15, 67-78. [CrossRef] [PubMed]

4. Martina, B.E.E.; Koraka, P.; Osterhaus, A.D.M.E. Dengue Virus Pathogenesis: An Integrated View. Clin. Microbiol. Rev. 2009, 22, 564-581. [CrossRef] [PubMed]

5. Malavige, G.N.; Ogg, G.S. Pathogenesis of vascular leak in dengue virus infection. Immunology 2017, 151, 261-269. [CrossRef] [PubMed]

6. Lannes, N.; Summerfield, A.; Filgueira, L. Regulation of inflammation in Japanese encephalitis. J. Neuroinflamm. 2017, 14, 1-11. [CrossRef] [PubMed]

7. Meeran, H.; Messent, M. The systemic inflammatory response syndrome. Trauma 2001, 3, 89-100. [CrossRef]

8. Harizi, H.; Corcuff, J.B.; Gualde, N. Arachidonic-acid-derived eicosanoids: Roles in biology and immunopathology. Trends Mol. Med. 2008, 14, 461-469. [CrossRef] [PubMed]

9. Preeyasombat, C.; Treepongkaruna, S.; Sriphrapradang, A.; Choubtum, L. The role of prostacyclin (PGI2) and thromboxane A2 (TXA2) in pathogenesis of dengue hemorrhagic fever (DHF). J. Med. Assoc. Thail. 1999, $82,16-21$. 
10. Loke, W.M.; Chow, A.Y.; Lam, K.; Sing, M.; Lee, C.J.; Halliwell, B.; Lim, E.C.H.; Quek, A.M.L.; Ooi, E.E.; Seet, R.C.S. Augmentation of 5-lipoxygenase activity and expression during dengue serotype-2 infection. Virol. J. 2013, 10, 1-9. [CrossRef] [PubMed]

11. Lin, C.K.; Tseng, C.K.; Wu, Y.H.; Liaw, C.C.; Lin, C.Y.; Huang, C.H.; Chen, Y.H.; Lee, J.C. Cyclooxygenase-2 facilitates dengue virus replication and serves as a potential target for developing antiviral agentes. Sci. Rep. 2017, 7, 1-15. [CrossRef]

12. Bozza, P.T.; Bakker-abreu, I.; Navarro-xavier, R.A.; Bandeira-melo, C. Lipid body function in eicosanoid synthesis: An update. Prostaglandins Leukot. Essent. Fat. Acids 2011, 85, 205-213. [CrossRef] [PubMed]

13. Bozza, P.T.; Melo, R.C.N.; Bandeira-Melo, C. Leukocyte lipid bodies regulation and function: Contribution to allergy and host defense. Pharmacol. Ther. 2007, 113, 30-49. [CrossRef] [PubMed]

14. Melo, R.C.N.; D’Avila, H.; Wan, H.C.; Bozza, P.T.; Dvorak, A.M.; Weller, P.F. Lipid Bodies in Inflammatory Cells: Structure, Function, and Current Imaging Techniques. J. Histochem. Cytochem. 2011, 59, 540-546. [CrossRef] [PubMed]

15. Herker, E.; Ott, M. Emerging Role of Lipid Droplets in Host/Pathogen Interactions. J. Biol. Chem. 2012, 287, 2280-2287. [CrossRef] [PubMed]

16. Carvalho, F.A.; Carneiro, F.A.; Martins, I.C.; Assunção-Miranda, I.; Faustino, A.F.; Pereira, R.M.; Bozza, P.T.; Castanho, M.A.R.B.; Mohana-Borges, R.; et al. Dengue Virus Capsid Protein Binding to Hepatic Lipid Droplets (LD) is Potassium Ion Dependent and is Mediated by LD Surface Proteins. J. Virol. 2012, 86, 2096-2108. [CrossRef] [PubMed]

17. Jindal, A.; Bruzzì, S.; Sutti, S.; Locatelli, I.; Bozzola, C.; Paternostro, C.; Parola, M.; Albano, E. Fat-laden macrophages modulate lobular inflammation in nonalcoholic steatohepatitis (NASH). Exp. Mol. Pathol. 2015, 99, 155-162. [CrossRef] [PubMed]

18. Mosquera, J.A.; Hernandez, J.P.; Valero, N.; Espina, L.M.; Añez, G.J. Ultrastructural studies on dengue virus type 2 infection of cultured human monocytes. Virol. J. 2005, 2, 1-14. [CrossRef] [PubMed]

19. Dennis, E.A.; Norris, P.C. Eicosanoid storm in infection and inflammation. Nat. Rev. Immunol. 2015, 15, 511-523. [CrossRef] [PubMed]

20. Ricciotti, E.; Fitzgerald, G.A. Prostaglandins and Inflammation. Arterioscler. Thromb. Vasc. 2011, 31, $986-1001$. [CrossRef] [PubMed]

21. Hedi, H.; Norbert, G. 5-Lipoxygenase Pathway, Dendritic Cells, and Adaptive Immunity. J. Biomed. Biotechnol. 2004, 2004, 99-105. [CrossRef] [PubMed]

22. Livak, K.J.; Schmittgen, T.D. Analysis of Relative Gene Expression Data Using Real-Time Quantitative PCR and the $2^{-\Delta \Delta C t}$ Method. Methods 2001, 25, 402-408. [CrossRef] [PubMed]

23. Applied Biosystems. Relative Quantitation Using Comparative C. 2006. Available online: papers3:/ / publication/ uuid/BDBB14AF-36A9-4B7B-875F-4E9A02186C90.pdf (accessed on 11 May 2017).

24. Pacidônio, E.C.; Caragata, E.P.; Alves, D.M.; Marques, J.T.; Moreira, L.M. The impact of Wolbachia infection on the rate of vertical transmission of dengue virus in Brazilian Aedes aegypti. Parasites Vectors 2017, 10, 296. [CrossRef] [PubMed]

25. Richardson, J.; Molina-cruz, A.; Salazar, M.I.; Black, W. Quantitative Analysis of Dengue-2 Virus RNA during the Extrensic Incubation Period in Individual Aedes aegypti. Am. J. Trop. Med. Hyg. 2006, 74, 132-141. [PubMed]

26. Oliveira, E.S. Imunologia Celular e Molecular, LB in Different Populations of Leukocytes of Dengue Patients; Instituto René Rachou: Belo Horizonte, Brazil, 2018.

27. Simmons, C.P.; Mcpherson, K.; van Vinh, N.; Tam, D.T.H.; Young, P.; Mackenzie, J.; Wills, B. Recent advances in dengue pathogenesis and clinical management. Vaccine 2015, 33, 7061-7068. [CrossRef] [PubMed]

28. Dorn, G.W.; Becker, M.W. Thromboxane A2 stimulated signal transduction in vascular smooth muscle. J. Pharmacol. Exp. Ther. 1993, 265, 447-456. [PubMed]

29. Hoggatt, J.; Pelus, L.M. Eicosanoid regulation of hematopoiesis and hematopoietic stem and progenitor trafficking. Leukemia 2010, 24, 1993-2002. [CrossRef] [PubMed]

30. Remuzzi, G.; FitzGerald, G.; Patrono, C. Thromboxane synthesis and action within the kidney. Kidney Int. 1992, 41, 1483-1493. [CrossRef] [PubMed]

31. Kalinski, P. Regulation of Immune Responses by Prostaglandin E2. J. Immunol. 2012, 27, 339-351. [CrossRef] [PubMed] 
32. White, R.K.; Montgomery, S. Leukotrienes: Inflammatory mediators-A review. Oral Surg. Oral Med. Oral Pathol. 1986, 61, 514-518. [CrossRef]

33. Samsa, M.M.; Mondotte, J.; Iglesias, N.G.; Assunção-Miranda, I.; Barbosa-Lima, G.; Da Poian, A.T.; Bozza, P.T.; Gamarnik, A.V. Dengue Virus Capsid Protein Usurps Lipid Droplets for Viral Particle Formation. PLoS Pathog. 2009, 5. [CrossRef] [PubMed]

34. Assunção-Miranda, I.; Amaral, F.; Bozza, F.; Fagundes, C.T.; Sousa, L.P.; Souza, D.G.; Pacheco, P.; Barbosa-Lima, G.; Gomes, R.N.; Bozza, P.T.; et al. Contribution of macrophage migration inhibitory fator to the pathogenesis of dengue virus infection. FASEB J. 2010, 24, 218-228. [CrossRef] [PubMed]

35. Wong, K.L.; Chen, W.; Balakrishnan, T.; Toh, Y.X.; Fink, K.; Wong, S.C. Susceptibility and Response of Human Blood Monocyte Subsets to Primary Dengue Virus Infection. PLoS ONE 2012, 7, e36435. [CrossRef] [PubMed]

36. Ojha, A.; Nandi, D.; Batra, H.; Singhal, R.; Annarapu, G.K.; Bhattacharyya, S.; Seth, T.; Dar, L.; Medigeshi, G.R.; Vrati, S.; et al. Platelet activation determines the severity of thrombocytopenia in dengue infection. Sci. Rep. 2017, 7, 1-10. [CrossRef] [PubMed]

37. Dalrymple, N.A.; Mackow, E.R. Roles for Endothelial Cells in Dengue Virus Infection. Adv. Virol. $2012,2012$. [CrossRef] [PubMed]

38. Ramadan, F.M.; Upchurch, G.R.; Keagy, B.A.; Johnson, G. Endothelial Cell Thromboxane Production and Its Inhibition by a Calcium-Channel Blocker. Ann. Thorac. Surg. 1990, 49, 916-919. [CrossRef]

39. Rocca, B.; Secchiero, P.; Ciabattoni, G.; Ranelletti, F.O.; Catani, L.; Guidotti, L.; Melloni, E.; Maggiano, N.; Zauli, G.; Patrono, C. Cyclooxygenase-2 expression is induced during human megakaryopoiesis and caracterizes newly formed platelets. Proc. Natl. Acad. Sci. USA 2002, 99, 7634-7639. [CrossRef] [PubMed]

40. Rocca, B.; Secchiero, P.; Celeghini, C.; Ranelletti, F.O.; Ciabattoni, G.; Maggiano, N.; Habib, A.; Ricerca, B.M.; Barbarotto, E.; Patrono, C.; et al. Modulation of the expression and activity of cyclooxygenases in normal and accelerated erythropoiesis. Exp. Hematol. 2004, 32, 925-934. [CrossRef] [PubMed]

(C) 2018 by the authors. Licensee MDPI, Basel, Switzerland. This article is an open access article distributed under the terms and conditions of the Creative Commons Attribution (CC BY) license (http://creativecommons.org/licenses/by/4.0/). 